\title{
Label-free quantitative proteomics analysis reveals the fate of colostrum proteins in the intestine of neonatal calves
}

\author{
X. X. Wang, ${ }^{1,2}$ R. W. Han, ${ }^{1}$ X. W. Zhao, ${ }^{2} \odot$ D. W. Huang, ${ }^{2}$ H. L. Zhu, ${ }^{2} \odot$ T. Wu, ${ }^{2}$ Y. X. Qi, ${ }^{2}$ Y. X. Yang, ${ }^{1,2 *} \odot$ \\ and G. L. Cheng ${ }^{2}$ \\ ${ }^{1}$ College of Food Science and Engineering, Qingdao Agricultural University, Qingdao 266109, China \\ ${ }^{2}$ Anhui Key Laboratory of Livestock and Poultry Product Safety Engineering, Institute of Animal Science and Veterinary Medicine, \\ Anhui Academy of Agricultural Sciences, Hefei 230031, China
}

\section{ABSTRACT}

The contribution of intestinally absorbed colostral immunoglobulins to the transmission of passive immunity is widely reported in neonatal calves. However, changes in the colostral proteome in the gastrointestinal digesta remain unclear. Therefore, this study aimed to investigate changes in colostral proteome affected by gastrointestinal proteases in neonatal calves. Twentyone neonatal Holstein calves were used in this study, including 18 colostrum-fed calves slaughtered at 8 (CI, $\mathrm{n}=6), 24(\mathrm{CII}, \mathrm{n}=6)$, and $36 \mathrm{~h}(\mathrm{CIII}, \mathrm{n}=6)$ postpartum and 3 milk-fed calves slaughtered $24 \mathrm{~h}$ postpartum $(\mathrm{MI}, \mathrm{n}=3)$. The ingested colostrum and milk samples were collected from the mid-jejunum segment, following the sacrifice. The undigested colostrum or milk along with their ingested colostrum or milk samples were investigated using a label-free proteomics approach. Hierarchical clustering and principal component analysis of the quantified proteins revealed that the ingested colostrum from the CII and CIII groups and the ingested mature milk from the MI group appeared to share similar patterns. Analysis of the intestinal digesta revealed a time-dependent decrease in caseins, lactoferrin, and osteopontin protein levels, and an increase in cationic trypsin, chymotrypsin, and carboxypeptidase. Several protease inhibitors, such as $\alpha$-1-antiproteinase, $\alpha$-2-antiplasmin, and early lactation protein, were identified in the colostrum and intestinal digesta. In addition, we detected identical levels in the intestinal digesta and colostrum for albumin, $\alpha$-1-acid glycoprotein, and plasminogen. Pathway analysis indicated that proteins increased in the intestinal digesta belonged to the following categories: biosynthesis of antibiotics, carbon metabolism, and biosynthesis of amino acids. These results indicated that selected colostral proteins

Received February 28, 2020.

Accepted June 12, 2020.

*Corresponding author: yyongxin@yahoo.com were digested by gastrointestinal proteases, contributing to their intestinal absorption in calves. These findings provide new insights into the fate of the colostral proteome in the gastrointestinal tract and may aid in the identification of factors contributing to health management in neonatal calves.

Key words: colostrum, intestine, neonatal calf, proteomics

\section{INTRODUCTION}

Colostrum contains high concentrations of bioactive substances, nutrients, and hormones to promote maturation and growth of calves (Kertz et al., 2017). Colostral IgG is crucial for the passive transfer of immunity to neonatal calves in the first $24 \mathrm{~h}$ of life (Shivley et al., 2018). In general, the apparent efficiency of colostral IgG absorption is approximately 30\% (Saldana et al., 2019). Intestinal absorption of other colostral components also contributes to supporting intestinal maturation and host defenses. The colostrum contains extremely high concentrations of protease inhibitors to protect its immunoactive substances against proteolytic cleavage (McGrath et al., 2016). However, the presence of inhibitors does not completely prevent the digestion of colostral proteins in the gastrointestinal tract of neonatal lambs fed colostrum, as reported in a previous study (Yvon et al., 1993). Additionally, the protein profiles of bovine colostrum digestion performed in vitro and in vivo differed when analyzed on tris-tricine gels (Morgan et al., 2014), due to the effect of colostral intake on the activity of digestive enzymes in the gastrointestinal tract (Blättler et al., 2001). Interestingly, studies on serum metabolites indicated that the concentrations of total free essential amino acids and several individual amino acids were increased (Zanker et al., 2000; Miyazaki et al., 2017). This result was further supported by metabolomic analyses of serum and ingested colostrum from the gastrointestinal tract of neonatal calves (Qi et al., 2018; Zhao et al., 2018). Col- 
lectively, available data suggest that colostral proteins could be degraded into amino acids in the intestinal digesta and some components of the digested colostrum are absorbed by the intestine and transported into the bloodstream. However, the full spectrum of changes occurring in the colostrum proteome as it passes through the gastrointestinal tract of neonatal calves remains unclear.

Proteomic strategies allow the simultaneous characterization of the relative protein abundance in milk samples, and label-free approaches have similar reproducibility and sensitivity to label-based approaches (Nissen et al., 2017; Cao et al., 2019). Label-free approaches are widely used to quantify the global profile changes in protein abundance, regardless of the number of samples and the need to introduce stable isotopes into samples (Neilson et al., 2011). Based on the proteomics approaches, changes in protein profiles of colostrum and mature milk were identified (Nissen et al., 2017; Cao et al., 2019), and the colostral proteins digested by gastric protease and assimilated by the intestine in piglets receiving colostrum were characterized (Danielsen et al., 2011). Thus, these results provide clues as to how protein abundance of the colostrum is affected by gastrointestinal proteases in neonatal calves.

We hypothesized that the fate of the colostral proteome in the gastrointestinal tract of neonatal calves correlated with intestinal absorption and could be revealed using a label-free proteomics approach. In the current study, colostrum, mature milk, and their digesta were collected from the intestines of neonatal calves, and shotgun proteomics was used to investigate the comprehensive changes in protein abundance. Our results provide new information on the composition of the digested colostral proteome and a better understanding of intestinal digestion and absorption in neonatal calves.

\section{MATERIALS AND METHODS}

\section{Animals, Experimental Procedures, and Sample Collection}

Animal care and experimental procedures were approved by the Animal Care Advisory Committee of the Anhui Academy of Agricultural Sciences. The collection of undigested colostrum and mature milk samples, as well as the ingested colostrum and milk samples from the mid-jejunum segment, was performed as described previously (Qi et al., 2018; Zhao et al., 2018). In brief, neonatal Chinese Holstein bull calves were immediately separated from dams after calving. Pooled colostrum or mature milk was incubated at $40^{\circ} \mathrm{C}$ in a water bath and provided to each calf via an esophageal tube. Twenty- seven calves were separated into 5 groups as follows: (1) 6 calves were not administered any colostrum or milk and were slaughtered $2 \mathrm{~h}$ postpartum; (2) 6 calves were administered with a meal of pooled colostrum at 1 to $2 \mathrm{~h}$ and slaughtered $8 \mathrm{~h}$ postpartum (CI group); (3) 6 calves were administered with 2 meals of colostrum at 1 to $2 \mathrm{~h}$ and 10 to $12 \mathrm{~h}$ postpartum and slaughtered $24 \mathrm{~h}$ postpartum (CII group); (4) 6 calves were administered with 3 meals of colostrum at 1 to $2 \mathrm{~h}, 10$ to $12 \mathrm{~h}$, and 22 to $24 \mathrm{~h}$ postpartum and slaughtered $36 \mathrm{~h}$ postpartum (CIII group); and (5) 3 calves were administered with mature milk and slaughtered $24 \mathrm{~h}$ postpartum (MI group). Following the sacrifice, 18 individual ingested colostrum samples were collected from the mid-jejunum segment of the CI, CII, and CIII groups. Three individual ingested mature milk samples were collected from the mid-jejunum segment of the MI group. In addition, 3 pooled colostrum and 3 pooled mature milk samples that were used to feed the neonatal calves were used as control. A workflow diagram is shown in Supplemental Figure S1 (https://doi.org/ 10.3168/jds.2020-18439). The samples were stored at $-80^{\circ} \mathrm{C}$ until use.

\section{Sample Preparation Procedure}

The samples were thawed at $4^{\circ} \mathrm{C}$, and equal volumes of 2 ingested colostrum samples from each time point were pooled to create CI, CII, and CIII groups. The final list of samples included 3 pooled undigested colostrum samples, 3 pooled undigested milk samples, 3 individual ingested milk samples, and 9 ( $\mathrm{n}=3$ for each time point) pooled ingested colostrum samples. These samples were centrifuged at $4,000 \times g$ for $30 \mathrm{~min}$ at $4^{\circ} \mathrm{C}$. The supernatant containing milk protein was collected, and protein concentrations were determined by the bicinchoninic acid assay (Beyotime Biotechnology, Shanghai, China). The filter-aided sample preparation was performed as previously described (Yang et al., 2018). Briefly, $100 \mu \mathrm{g}$ proteins from each sample were boiled in water at $95^{\circ} \mathrm{C}$ for 8 min with a solution containing $4 \%$ sodium dodecyl sulfate, $100 \mathrm{~m} M$ Tris $\mathrm{HCl}$, and $100 \mathrm{~m} M$ dithiothreitol. Samples were then cooled and mixed with $200 \mu \mathrm{L}$ of $8 M$ urea and $100 \mathrm{mM}$ Tris $\mathrm{HCl}, \mathrm{pH} 8.0$, vortexed, and transferred into the ultrafilter tube (10-kDa cutoff, Sartorius, Göttingen, Germany) followed by centrifugation at $14,000 \times g$ for 30 min at $25^{\circ} \mathrm{C}$. Subsequently, the samples were mixed with $100 \mu \mathrm{L}$ of $50 \mathrm{~m} M$ iodoacetamide solution and incubated in the dark for $50 \mathrm{~min}$ at $25^{\circ} \mathrm{C}$. Finally, the samples were mixed with $120 \mu \mathrm{L}$ of trypsin buffer $(3 \mu \mathrm{g}$ of trypsin in $50 \mathrm{~m} M$ ammonium bicarbonate) and then incubated for 16 to $18 \mathrm{~h}$ at $37^{\circ} \mathrm{C}$. The tryptic peptides were centrifuged and then dried. 


\section{Liquid Chromatography-Tandem Mass Spectrometry Analysis}

Dried peptides were resuspended with $0.1 \%$ formic acid, centrifuged, and transferred into a tube. Peptide mixtures were processed using an EASY-nLC 1200 system coupled with a Q Exactive (Thermo Fisher Scientific, Waltham, MA). The MS analysis of peptides was performed following the protocol published by Yang et al. (2020) with the slight modifications. Briefly, after the columns were equilibrated with $95 \%$ (vol/vol) buffer $\mathrm{A}(0.1 \%$ formic acid), peptide mixtures were loaded onto the trap column $(20 \mathrm{~mm} \times 100 \mu \mathrm{m}, 5 \mu \mathrm{m})$ via an autosampler and separated on a reverse-phase column (120 mm × $75 \mu \mathrm{m}, 3 \mu \mathrm{m}$, Thermo Fisher Scientific) at a flow rate of $300 \mathrm{~nL} / \mathrm{min}$. The elution procedure was the following: buffer B ( $0.1 \%$ formic acid and $85 \%$ acetonitrile) 5 to $8 \%$ within 2 min, 8 to $23 \%$ within 88 min, 23 to $40 \%$ within $10 \mathrm{~min}, 40$ to $100 \%$ within 8 min, and held at $100 \%$ for $12 \mathrm{~min}$.

The Q Exactive was operated in the positive ion mode with a data-dependent acquisition and a 300 to 1,800 mass/charge $(\mathrm{m} / \mathrm{z})$. Resolving power was set at 70,000 at $200 \mathrm{~m} / z$ for the survey MS scan and 17,500 at $200 \mathrm{~m} / \mathrm{z}$ for the tandem MS (MS/MS) scan. The top 20 most abundant precursor ions were selected based on the survey MS scan and subjected to MS/ MS analysis via higher-energy collisional dissociation. The automatic gain control target value for the MS and the MS/MS scans were set at $1 \times 10^{6}$ and $1 \times 10^{5}$, respectively. The maximum ion injection time was 50 $\mathrm{ms}$, the isolation window was $1.6 \mathrm{Th}$, and the value of normalized collision energy was $27 \mathrm{eV}$. Raw data files were acquired by Xcalibur 3.0 software (Thermo Fisher Scientific).

\section{Protein Identification and Quantitation}

Raw files were used to search against the Bos taurus database downloaded from UniProt (46,721 entries, 2019) using Maxquant software (version 1.6.0.16; Cox and Mann, 2008). The searching parameters were as follows: 2 missed cleavage sites, MS/MS tolerance for 20 ppm, a fixed modification set (carbamidomethylation of cysteine), and a variable modification set (oxidation of methionine and acetylation of the protein $\mathrm{N}$ terminus). The decoy database pattern was set as the reversed version of the target database. Peptide spectral matching and protein identification were filtered using a false discovery rate of less than $1 \%$. Proteins with at least 2 unique peptides and identified in all 3 biological replicates from each group were quantified using a label-free quantification algorithm and used for further analysis.

\section{ELISA Quantification Assays}

The lactoferrin concentrations from the undigested colostrum and mature milk and the ingested colostrum and mature milk collected from the mid-jejunum segment of neonatal calves were determined using an ELISA kit (Bethyl Laboratories, Montgomery, TX), according to the manufacturer's instructions.

\section{Data Analysis}

The matrix of the identified proteins from the 6 groups was analyzed with the Perseus software (Tyanova et al., 2016). The relative abundances of the identified proteins were processed with binary transformation and imputation missing values. For the statistical analysis, undigested colostrum and ingested colostrum from CI, CII, and CIII groups were analyzed using one-way ANOVA, and undigested milk and ingested milk were analyzed using the $t$-test. In addition, ingested colostrum from CII group and ingested milk were analyzed using the $t$-test. Changes in proteins with $P$-values less than 0.05 and fold-change more than 2 were defined as significant. In addition, comparison of protein values among the undigested colostrum and milk and ingested colostrum and milk collected from the jejunal segment were performed using hierarchical clustering and principal component analysis (PCA). For ELISA data, statistical analysis was performed using the statistical package of Social Sciences software (version 19.0, IBM, Chicago, IL). Changes in the lactoferrin concentrations among the undigested colostrum and ingested colostrum from the CI, CII, and CIII groups were analyzed using one-way ANOVA. Changes in the lactoferrin concentrations between undigested and ingested milk were analyzed using the $t$-test, in which the sample of the individual calf was considered as the experimental unit. Furthermore, functional analysis of the identified proteins was performed using the DAVID functional annotation tools (david.ncifcrf.gov).

\section{RESULTS}

\section{Proteomic Characterization of Milk Proteins}

To obtain the robust results, proteins identified in 3 biological replicates from each group were applied in the following analysis. A total of 320 and 313 proteins were identified in the colostrum and mature milk, respectively. From the ingested colostrum samples, 740, 768, and 1,182 proteins were identified from the CI, CII, and CIII groups, respectively. The MI group had 1,318 proteins meeting the set criteria. All quantified 
proteins among the 6 studied groups were subjected to clustering analysis and PCA. Clustering analysis revealed that the ingested colostrum from the CII and CIII groups and ingested mature milk from the MI group appeared to share a similar pattern and were grouped into a subcluster. The ingested colostrum from the CI group was closely correlated with this subcluster, with which it formed a larger cluster, whereas the undigested colostrum and milk clustered alone (Figure 1). The PCA score plots indicated that proteome profiles were obviously clustered together, according to the sample collections. Temporal proteome changes were observed when undigested colostrum was compared with ingested colostrum from groups CI, CII, and CIII, which were similar to the changes observed when milk was compared with ingested milk. Based on the loading plots, we found that several proteins, such as $\beta$-casein, $\kappa$-casein, $\alpha_{S_{2}}$-casein, and cytoplasmic aconitate hydratase, contributed to the changes observed in the comparison between undigested and digested colostrum and milk (Figure 2).

\section{Differentially Expressed Proteins Among the Studied Groups}

Compared with undigested colostrum, 201 proteins were significantly decreased in the ingested colostrum, including protein OS-9, histatherin, and aspartyltRNA synthetase which were completely degraded in the ingested colostrum. Moreover, $\alpha_{\mathrm{S} 1}$-casein, $\beta$-casein, $\kappa$-casein, $\alpha_{\mathrm{S} 2}$-casein, $\beta$-2-microglobulin, clusterin, and osteopontin showed a substantial decrease in the ingested colostrum from the CII group compared with the undigested colostrum. Furthermore, IgG, complement C3, xanthine dehydrogenase/oxidase, and $\alpha-2$ macroglobulin were decreased in the ingested colostrum from the CII and CIII groups. Additionally, 918 proteins, including 78 proteins identified in the colostrum, were significantly increased in the ingested colostrum. Among these, the proteins uniquely identified in the ingested colostrum were cationic trypsin, chymosin, dipeptidyl peptidase 4, and carboxypeptidase A1, B, and B2, associated with proteolytic activity; $\beta$-adaptin, retinol-binding protein (RBP) 1, and RBP2, correlated with transport activity; and glutathione peroxidase 1, catalase, and manganese superoxide dismutase, involved in antioxidant activity. A total of 41 proteins, including $\alpha$-lactalbumin, albumin, plasminogen, $\alpha$-2-antiplasmin, early lactation protein (ELP), and antithrombin-III remained unchanged after colostrum digestion (Supplemental Table S1, http://doi.org/10.3168/jds.2020 -18439). In addition, ELISA assays revealed that colostral lactoferrin concentrations decreased significantly in a time-dependent manner following colostrum inges- tion. Temporal changes in lactoferrin determined by ELISA assays were consistent with the results obtained from proteomic data (Supplemental Figure S2, http:// doi.org/10.3168/jds.2020-18439).

Compared with mature milk, 179 proteins were significantly downregulated, 1,029 proteins were significantly upregulated, and the levels of 44 proteins were not significantly different in the ingested mature milk (Supplemental Table S2, http://doi.org/10 $.3168 /$ jds.2020-18439). Most of the abundant milk proteins, including $\alpha_{\mathrm{S} 1^{-}}$casein, $\beta$-casein, $\kappa$-casein, $\alpha_{\mathrm{S}^{-}}$ casein, $\beta$-2-microglobulin, lactoferrin, $\beta$-lactoglobulin, $\alpha$-lactalbumin, lactadherin, and $\operatorname{IgG}$ were downregulated, whereas ingested milk proteins, including $\alpha$-2-antiplasmin, $\alpha$-1-antiproteinase, intestinal fatty acid-binding protein, lactase, and peroxiredoxin-1, were upregulated. Albumin, plasminogen, antithrombin-III, serotransferrin, hemopexin, and $\alpha$-2-macroglobulin levels did not vary between indigested and undigested milk. ELISA assays were consistent with proteomic data about the difference in lactoferrin levels between undigested and ingested milk (Supplemental Figure S2).

Changes in proteins between the ingested milk and the colostrum from the CII group were analyzed. We found 151 proteins, including IGK, lactoferrin, polymeric immunoglobulin receptor, and IgG significantly decreased, and 617 proteins, including cytosolic NADPisocitrate dehydrogenase, $\alpha$-enolase, and cytoplasmic aconitate hydratase significantly increased in the ingested milk compared with that in the ingested colostrum from the CII group.

The changes in the protein profiles of undigested and ingested colostrum appeared similar to those observed in undigested and ingested milk. The relative abundance of caseins, osteopontin, glycosylation-dependent cell adhesion molecule 1 , and $\beta$-2-microglobulin decreased at least $96 \%$ in the intestinal digesta of CII group compared with that in the undigested colostrum. A similar observation was made in calves fed with milk in the MI group. Albumin, $\alpha-1$-acid glycoprotein, and plasminogen levels were not altered in the intestinal digesta compared with those in undigested colostrum or milk samples. Several proteins, including cationic trypsin, chymosin, chymotrypsin-C, and carboxypeptidase A1 and $\mathrm{B}$ secreted into the intestinal digesta did not vary between calves fed with colostrum and milk. However, we observed several differences in the protein profiles of colostrum and ingested colostrum compared with those of milk and digested milk. Relative abundance of xanthine dehydrogenase/oxidase did not vary between the intestinal digesta of the CII group and undigested colostrum, whereas xanthine dehydrogenase/oxidase decreased approximately $89 \%$ in the ingested milk com- 

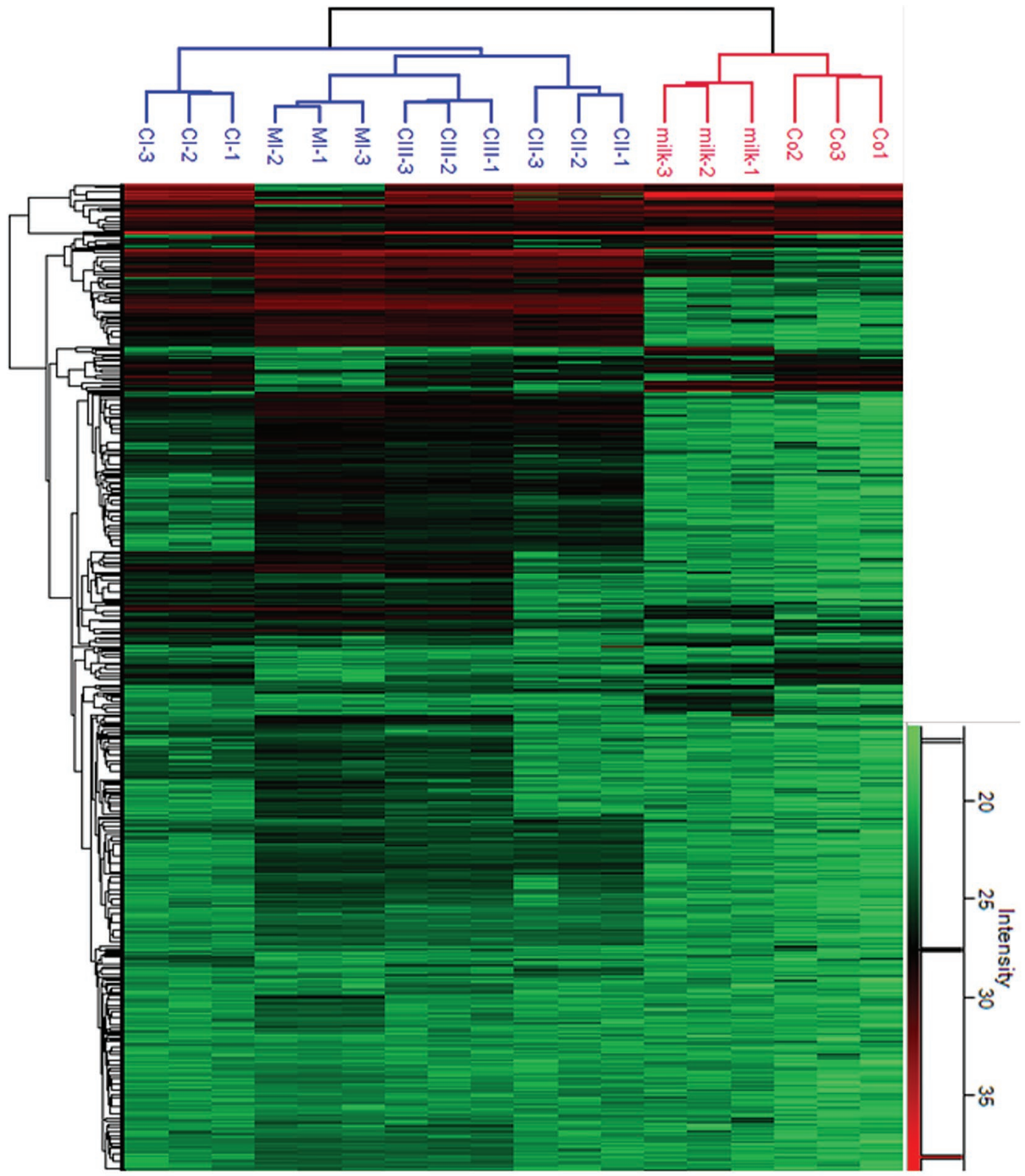

Figure 1. Hierarchical clustering analysis of the identified proteins among the colostrum and milk, and ingested colostrum and milk collected from the mid-jejunum segment. Co indicates colostrum; CI, CII, and CIII indicate ingested colostrum samples collected from the mid-jejunal segment at approximately 8, 24, and $36 \mathrm{~h}$ after birth, respectively; MI indicates ingested milk samples collected from the mid-jejunal segment at approximately $24 \mathrm{~h}$ after birth.

pared with that in undigested milk. Sulfhydryl oxidase, $\alpha$-lactalbumin, and hemoglobin subunit $\alpha$ levels were not different in the ingested colostrum compared with those in the undigested colostrum but were downregulated in the ingested milk compared with those in the undigested milk. Moreover, $\alpha$-2-macroglobulin, serotransferrin, $\alpha$-1B-glycoprotein, and hemopexin levels were lower in the ingested colostrum as compared with those in colostrum but remained unchanged in milk and ingested milk.

\section{Functional Analysis of Differentially Expressed Proteins}

According to protein annotations, most of the downregulated proteins in the ingested colostrum were associated with response to stimulus, protein metabolic process, transport, and system development, based on analyzing the biological processes, and were associated with protein binding, enzyme regulator activity, molecular function regulator, and receptor binding, based 
on molecular functions (Figure 3). The downregulated proteins were assigned into complement and coagulation cascades, Staphylococcus aureus infection, extracellular matrix-receptor interaction, phagosome, and peroxisome proliferator-activated receptor signaling pathway (Table 1). Moreover, upregulated proteins in the ingested colostrum originated from the extracellular region, vesicle, extracellular exosome, and nucleus, based on the cellular component analysis, and were associated with the following biological processes: protein metabolism, small molecule metabolism, catabolism, and phosphorus metabolic processes. The same proteins were also associated with the following molecular functions: catalytic activity, protein binding, hydrolase activity, small molecule binding, and nucleotide binding. Upregulated proteins were significantly involved in multiple metabolic pathways, such as biosynthesis of antibiotics, carbon metabolism, biosynthesis of amino acids, and amino sugar and nucleotide sugar metabolism. Furthermore, proteins that remained unchanged through digestion were involved in the following biological process: response to stimulus, protein metabolic process, and defense response, and were associated with the following molecular functions: protein binding, enzyme regulator activity, and receptor binding.
These proteins were also assigned to complement and coagulation cascades, Staphylococcus aureus infection, peroxisome proliferator-activated receptor signaling pathway, and fatty acid biosynthesis.

Collectively, our data suggest that the downregulated, upregulated, and unchanged proteins in the ingested milk compared with those in the undigested milk are associated with biological processes, cellular components, molecular functions, and pathways that were similar to those observed for the ingested colostrum (Figure 3 and Supplemental Table S3, http://doi .org/10.3168/jds.2020-18439).

\section{DISCUSSION}

Developmental changes in colostral proteins as they pass through the gastrointestinal tract of neonatal calves were investigated using a label-free proteomics approach. Although the colostrum contributes to passive immunity transfer and intestinal protection of the neonatal calves, little information is available regarding the changes in the digestion and absorption of colostral proteins in the neonatal calf intestine (Danielsen et al., 2011). Our results improve the understanding of how the time-dependent breakdown of colostral proteins is
A

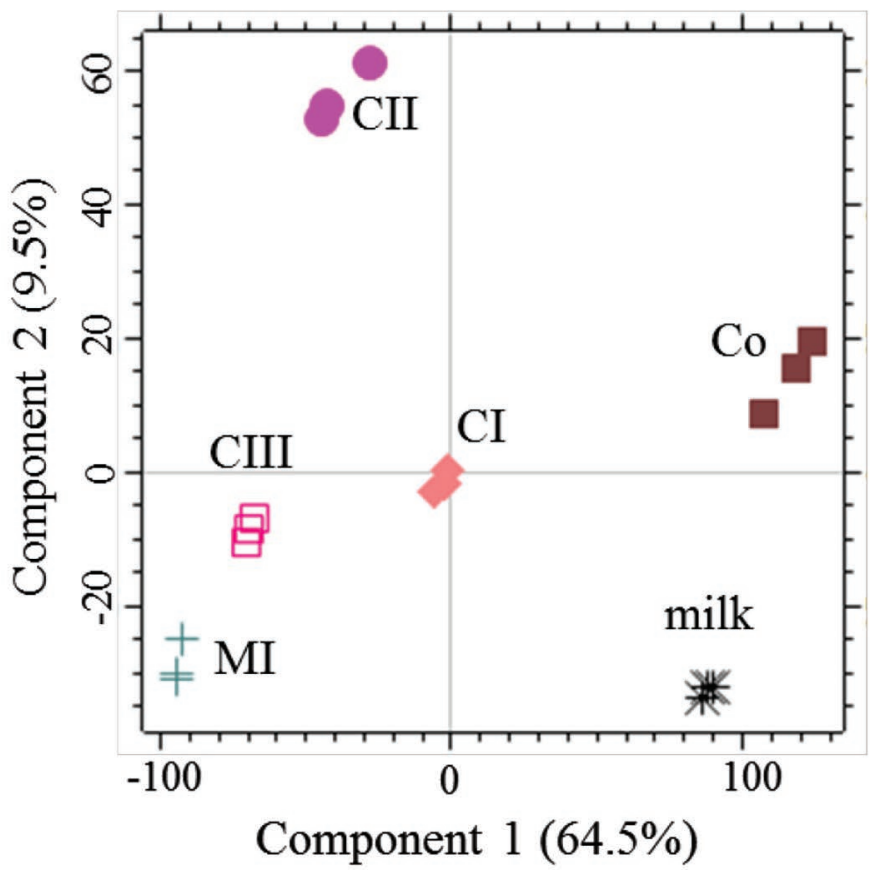

B

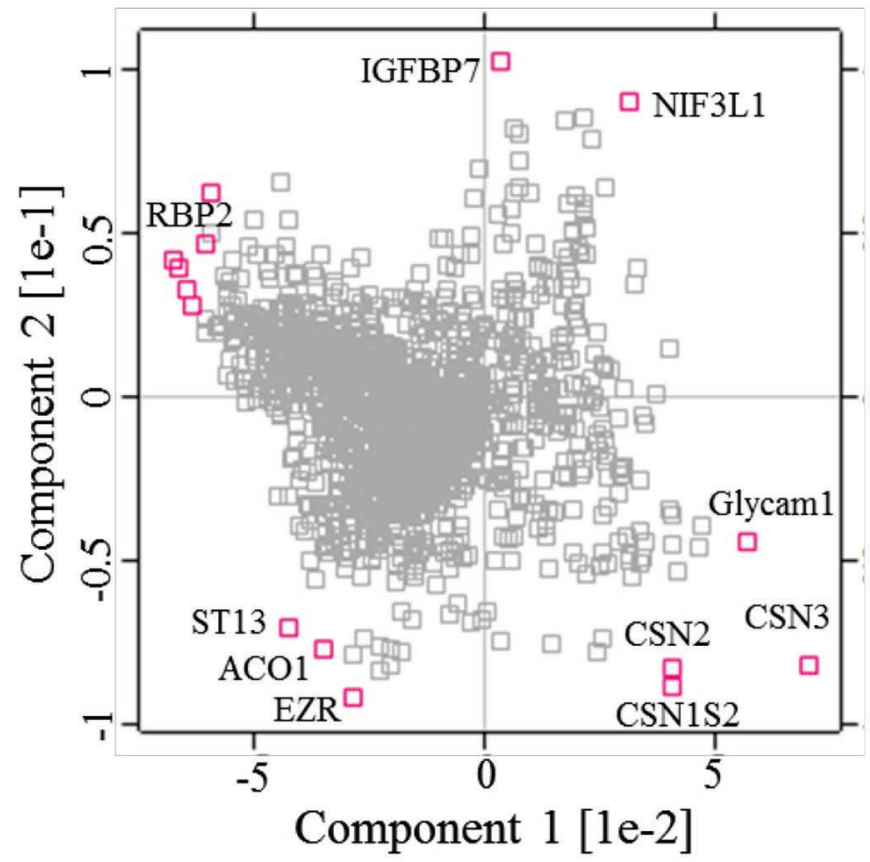

Figure 2. (A) Score plots and (B) corresponded loading plots of the principal component analysis of the identified proteins among the colostrum and milk, and ingested colostrum and milk collected from the mid-jejunal segment. Co indicates colostrum; CI, CII, and CIII indicate ingested colostrum samples collected from the mid-jejunal segment at approximately 8, 24, and 36 h after birth, respectively; MI indicates ingested milk samples collected from the mid-jejunal segment at approximately $24 \mathrm{~h}$ after birth. 

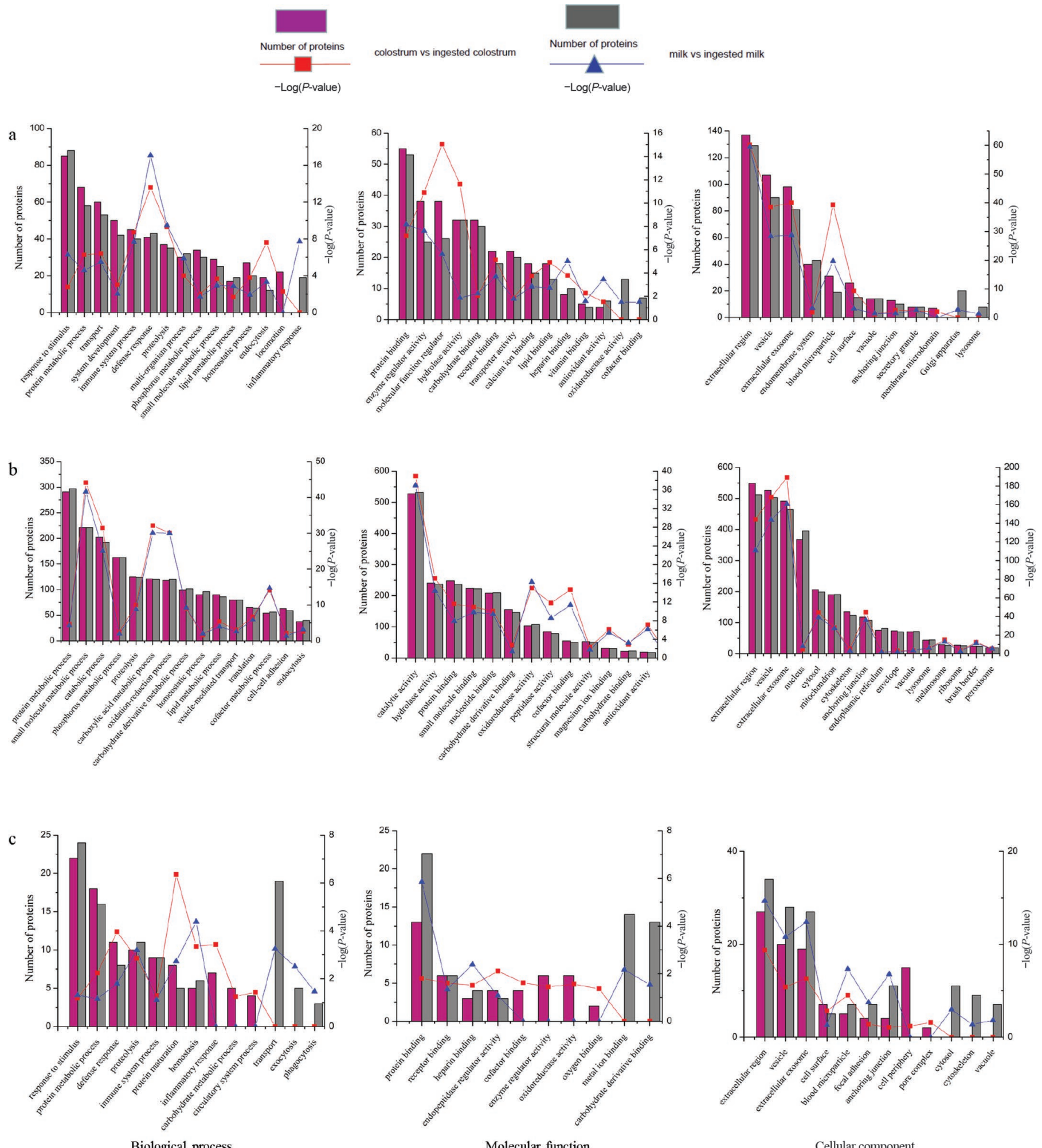

Molecular function
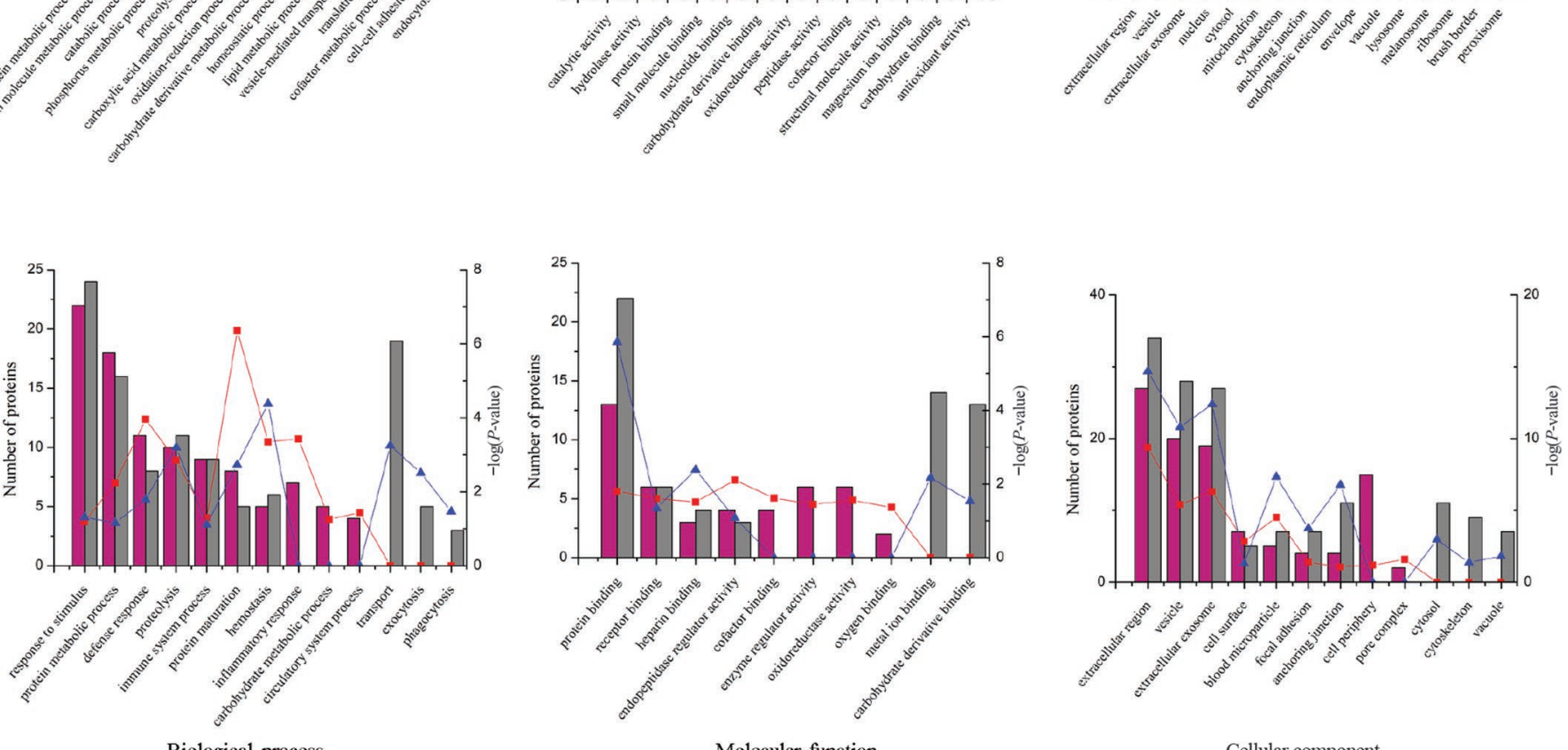

Figure 3. Function annotations of (A) downregulated, (B) upregulated, and (C) unchanged proteins from undigested colostrum or milk to the ingested colostrum or milk in the intestinal digesta. 
Table 1. Metabolic pathways of the identified proteins between the undigested colostrum and ingested colostrum collected from the jejunal segment with $P \leq 0.05$

\begin{tabular}{|c|c|c|c|c|c|}
\hline Pathway name ${ }^{1}$ & Counts $^{2}$ & $\mathrm{Hits}^{3}$ & Percent & $P$-value & Fold enrichment \\
\hline \multicolumn{6}{|l|}{$\begin{array}{l}\text { Decreased proteins in the ingested colostrum } \\
\text { compared with the undigested colostrum }\end{array}$} \\
\hline Complement and coagulation cascades & 16 & 74 & 8.94 & $<0.001$ & 16.00 \\
\hline Staphylococcus aureus infection & 11 & 59 & 6.15 & $<0.001$ & 13.80 \\
\hline ECM-receptor interaction & 8 & 87 & 4.47 & $<0.001$ & 6.81 \\
\hline Phagosome & 10 & 158 & 5.59 & $<0.001$ & 4.68 \\
\hline Protein processing in endoplasmic reticulum & 8 & 169 & 4.47 & 0.007 & 3.50 \\
\hline PPAR signaling pathway & 5 & 70 & 2.79 & 0.014 & 5.29 \\
\hline Fat digestion and absorption & 4 & 45 & 2.23 & 0.022 & 6.58 \\
\hline Vitamin digestion and absorption & 3 & 22 & 1.68 & 0.034 & 10.09 \\
\hline PI3K-Akt signaling pathway & 10 & 347 & 5.59 & 0.042 & 2.13 \\
\hline \multicolumn{6}{|l|}{$\begin{array}{l}\text { Unchanged proteins in the ingested colostrum } \\
\text { compared with the undigested colostrum }\end{array}$} \\
\hline Complement and coagulation cascades & 9 & 74 & 23.08 & $<0.001$ & 34.01 \\
\hline Staphylococcus aureus infection & 3 & 59 & 7.69 & 0.017 & 14.22 \\
\hline PPAR signaling pathway & 3 & 70 & 7.69 & 0.024 & 11.98 \\
\hline Fatty acid biosynthesis & 2 & 13 & 5.13 & 0.044 & 43.02 \\
\hline \multicolumn{6}{|l|}{$\begin{array}{l}\text { Increased proteins in the ingested colostrum } \\
\text { compared with the undigested colostrum }\end{array}$} \\
\hline Biosynthesis of antibiotics & 89 & 206 & 9.13 & $<0.001$ & 5.25 \\
\hline Carbon metabolism & 56 & 109 & 5.74 & $<0.001$ & 6.25 \\
\hline Biosynthesis of amino acids & 33 & 71 & 3.38 & $<0.001$ & 5.65 \\
\hline Valine, leucine, and isoleucine degradation & 24 & 50 & 2.46 & $<0.001$ & 5.84 \\
\hline Fatty acid degradation & 21 & 41 & 2.15 & $<0.001$ & 6.23 \\
\hline Amino sugar and nucleotide sugar metabolism & 22 & 48 & 2.26 & $<0.001$ & 5.57 \\
\hline Glycolysis/gluconeogenesis & 24 & 63 & 2.46 & $<0.001$ & 4.63 \\
\hline Glyoxylate and dicarboxylate metabolism & 15 & 26 & 1.54 & $<0.001$ & 7.01 \\
\hline Proteasome & 19 & 46 & 1.95 & $<0.001$ & 5.02 \\
\hline Citrate cycle (tricarboxylic acid cycle) & 15 & 30 & 1.54 & $<0.001$ & 6.08 \\
\hline Peroxisome & 25 & 84 & 2.56 & $<0.001$ & 3.62 \\
\hline Pentose phosphate pathway & 14 & 27 & 1.44 & $<0.001$ & 6.30 \\
\hline Spliceosome & 31 & 129 & 3.18 & $<0.001$ & 2.92 \\
\hline Propanoate metabolism & 13 & 26 & 1.33 & $<0.001$ & 6.08 \\
\hline Protein processing in endoplasmic reticulum & 35 & 169 & 3.59 & $<0.001$ & 2.52 \\
\hline Glutathione metabolism & 18 & 54 & 1.85 & $<0.001$ & 4.05 \\
\hline Cysteine and methionine metabolism & 15 & 38 & 1.54 & $<0.001$ & 4.80 \\
\hline Pyruvate metabolism & 15 & 38 & 1.54 & $<0.001$ & 4.80 \\
\hline Fatty acid metabolism & 16 & 48 & 1.64 & $<0.001$ & 4.05 \\
\hline Alanine, aspartate and glutamate metabolism & 13 & 36 & 1.33 & $<0.001$ & 4.39 \\
\hline Lysosome & 26 & 126 & 2.67 & $<0.001$ & 2.51 \\
\hline 2-Oxocarboxylic acid metabolism & 9 & 18 & 0.92 & $<0.001$ & 6.08 \\
\hline Butanoate metabolism & 11 & 28 & 1.13 & $<0.001$ & 4.78 \\
\hline$\beta$-Alanine metabolism & 12 & 34 & 1.23 & $<0.001$ & 4.29 \\
\hline Arginine biosynthesis & 9 & 19 & 0.92 & $<0.001$ & 5.76 \\
\hline Ribosome & 26 & 134 & 2.67 & $<0.001$ & 2.36 \\
\hline Fructose and mannose metabolism & 11 & 31 & 1.13 & $<0.001$ & 4.31 \\
\hline Bacterial invasion of epithelial cells & 18 & 77 & 1.85 & $<0.001$ & 2.84 \\
\hline Arginine and proline metabolism & 14 & 50 & 1.44 & $<0.001$ & 3.40 \\
\hline Tryptophan metabolism & 13 & 46 & 1.33 & $<0.001$ & 3.44 \\
\hline Starch and sucrose metabolism & 10 & 30 & 1.03 & $<0.001$ & 4.05 \\
\hline Purine metabolism & 27 & 176 & 2.77 & 0.002 & 1.87 \\
\hline Galactose metabolism & 9 & 31 & 0.92 & 0.003 & 3.53 \\
\hline Lysine degradation & 12 & 54 & 1.23 & 0.004 & 2.70 \\
\hline Renin-angiotensin system & 8 & 26 & 0.82 & 0.004 & 3.74 \\
\hline PPAR signaling pathway & 14 & 70 & 1.44 & 0.004 & 2.43 \\
\hline Endocytosis & 33 & 243 & 3.38 & 0.005 & 1.65 \\
\hline Antigen processing and presentation & 14 & 75 & 1.44 & 0.007 & 2.27 \\
\hline Adherens junction & 13 & 68 & 1.33 & 0.009 & 2.32 \\
\hline Synthesis and degradation of ketone bodies & 5 & 11 & 0.51 & 0.009 & 5.53 \\
\hline Nicotinate and nicotinamide metabolism & 8 & 32 & 0.82 & 0.013 & 3.04 \\
\hline Degradation of aromatic compounds & 3 & 3 & 0.31 & 0.019 & 12.16 \\
\hline Protein digestion and absorption & 13 & 84 & 1.33 & 0.041 & 1.88 \\
\hline Regulation of actin cytoskeleton & 26 & 212 & 2.67 & 0.041 & 1.49 \\
\hline Tyrosine metabolism & 8 & 40 & 0.82 & 0.042 & 2.43 \\
\hline Biosynthesis of unsaturated fatty acids & 6 & 24 & 0.62 & 0.042 & 3.04 \\
\hline Sulfur metabolism & 4 & 10 & 0.41 & 0.043 & 4.86 \\
\hline Oocyte meiosis & 16 & 114 & 1.64 & 0.045 & 1.71 \\
\hline Glycine, serine, and threonine metabolism & 8 & 41 & 0.82 & 0.047 & 2.37 \\
\hline
\end{tabular}

${ }^{1} \mathrm{PPAR}=$ proliferator-activated receptor

${ }^{2}$ Counts indicate the number of input proteins assigned into a given annotation category.

${ }^{3} \mathrm{Hits}$ indicate the number of proteins with a given term in the database. 
correlated with gastrointestinal-specific secretions and how colostral IgG is transferred across the small intestine of neonatal calves.

\section{Degradation of Colostral Proteins in the Intestinal Digesta}

Most colostral proteins were significantly decreased in the jejunum in a time-dependent manner after neonatal calves ingested colostrum. A previous proteomics analysis reported that several colostral proteins, such as $\kappa$-casein, apolipoprotein-E, and osteopontin, were digested in the stomach of piglets (Danielsen et al., 2011). Caseins hydrolysates are involved in multiple bioactive functions and possess healthful properties. $\beta$-Casomorphins derived from $\beta$-casein were associated with immunomodulatory, antioxidative, and satiety functions (Bueno-Gavilá et al., 2019; Enjapoori et al., 2019). The ingestion of casein phosphopeptides derived from casein hydrolysates contributed to calcium uptake in intestinal cells (Liu et al., 2018). Lactoferrin and lactoferrin-derived peptides have antimicrobial and immunomodulatory activities and are associated with multiple health benefits, including protection against infection and diseases in neonates (Telang, 2018; Haiwen et al., 2019). Osteopontin has immunomodulatory function and contributes to intestinal and early cognitive development (Jiang and Lönnerdal, 2016). Glycosylated osteopontin retains integrin-binding activity following digestion and contributes to the immunological signaling pathway (Christensen et al., 2020). The lactoferrin-osteopontin complex via their opposite charges may provide protection against proteolysis, promote proliferation and differentiation of intestinal cells, and enhance their individual functions (Liu et al., 2019). Furthermore, colostral and milk proteins, such as caseins and $\beta$-lactoglobulin were the most important sources of amino acids in the intestine digesta for neonatal lambs (Yvon et al., 1993). Increased levels of several amino acids, such as glutamate, aminobutyric acid, glutamine, and leucine, as a result of colostrum breakdown in the gastrointestinal tract in a time-dependent manner, were reported in our previous studies (Qi et al., 2018; Zhao et al., 2018). As discussed previously, we suggest that colostral proteins decreased in the intestine due to enzyme-mediated digestion, and their hydrolysates contribute to meeting the requirements of growth, development, and health needed by neonatal calves.

\section{Proteases in Colostrum and the Intestinal Digesta}

Several proteases, such as cationic trypsin, chymosin, chymotrypsin-C, cytosolic nonspecific dipeptidase, and carboxypeptidase A1 and B, were hardly quantified in the colostrum. However, their abundance significantly increased in the intestinal digesta of the calves receiving the colostrum. In vitro studies have shown that milk proteins are hydrolyzed by trypsin, chymosin, chymotrypsin, cathepsins, aminopeptidases, and dipeptidyl peptidase (Heinrich and Kulozik, 2011; Vorob'ev and Kochetkov, 2016). Several proteolytic enzymes, such as trypsin, cathepsin Z, dipeptidyl peptidase 4, and aminopeptidase $\mathrm{N}$, were observed in the gastrointestinal mucosa of neonatal calves fed with colostrum (Blättler et al., 2001; Nissen et al., 2012). Importantly, several novel proteases, such as membrane metalloendopeptidase, chymotrypsin-like elastase family member $2 \mathrm{~A}$, and carboxypeptidase $\mathrm{A} 1$ and $\mathrm{B}$, which contribute to colostral protein hydrolysis were identified in the intestinal digesta. Carboxypeptidase A1 and B are components of intestinal digestive enzymes that cleave dietary proteins and peptides to create amino acids (Gardell et al., 1988). The specific proteases that hydrolyze colostral proteins in the calves' intestine remain unclear and further investigations are needed. We propose that these proteins are secreted into the intestinal digesta by gastrointestinal cells and promote proteolysis as the colostrum passes through the gastrointestinal tract. Unexpectedly, the relative abundance of plasminogen did not change in the intestinal digesta compared with that in the colostrum. The conversion of plasminogen to active plasmin could be blocked by $\alpha$-1-antiproteinase or lactoferrin, which is a natural inhibitor of plasminogen activation (D'Alessandro et al., 2011; Zwirzitz et al., 2018). Our results indicated that the increase in abundance of proteases in the intestinal digesta contributed to the hydrolysis of colostral proteins resulting in the production of bioactive and nutritional substances. However, the mechanism underlying protease secretion by gastrointestinal cells and transport into the intestinal lumen, as well as their physiological functions, need further investigation.

\section{Protease Inhibitors in Colostrum and the Intestinal Digesta}

Several proteins with protease inhibitory activity, such as $\alpha$-1-antiproteinase, leukocyte elastase inhibitor, serpin I2, and serpin B6, increased; serpin A3-1, serpin A3-3, inter- $\alpha$-trypsin inhibitor decreased in the intestinal digesta, whereas ELP, $\alpha$-2-antiplasmin, and antithrombin-III were unchanged. Our results were consistent with previous studies that reported that $\alpha$-1-antiproteinase, serpin A3-1, and inter- $\alpha$-trypsin inhibitor were decreased in bovine milk compared with those in the colostrum (Nissen et al., 2017; Fahey et al., 2020). A similar comparative study in humans indicated 
that $\alpha$-1-antiproteinase, $\alpha$-2-antiplasmin, plasma serine protease inhibitor, and antithrombin-III concentrations were decreased in gastric samples compared with those in human milk (Demers-Mathieu et al., 2018). Among these, $\alpha$-1-antiproteinase, a serine protease inhibitor, is known to inhibit a wide variety of proteases, such as trypsin, elastase, chymotrypsin, plasmin, thrombin, and plasminogen (Dallas et al., 2015). Moreover, $\alpha$-2-antiplasmin and $\alpha-2$-macroglobulin derived from plasma protease inhibitors inhibited the activated plasmin by binding directly to it (Christensen et al., 1995; Law et al., 2013). Early lactation protein, a serine-type endopeptidase inhibitor, is known to be abundant in milk during early lactation (Piotte and Grigor, 1996; Yang et al., 2020). In the colostrum, ELP may have a role in protecting IgG against proteolysis. Interestingly, caseins had been shown to strongly inhibit trypsin and chymotrypsin in the intestinal lumen (Ohtani et al., 2003). In addition, peptides derived from caseins and whey proteins, as well as tryptophan, were resistant to hydrolysis by gastrointestinal enzymes in vitro (Tagliazucchi et al., 2018; Zheng et al., 2019). Although the role of colostral proteins and their hydrolysates in the intestinal digesta remains to be elucidated, they may increase the stability of immunological milk proteins within the gastrointestinal tract, allowing absorption of intact IgG by the small intestine and transport into the bloodstream of calves. Intact IgG, a key component of the colostrum, serves as a unique parameter in assessing the success or failure of the passive transfer of immunity in neonatal calves (Fischer et al., 2018). Colostral IgG protects itself against proteolysis through the protease inhibitors found in the colostrum and hydrolysates of caseins and whey proteins.

\section{Unique Proteins in the Intestinal Digesta}

Several transport-related proteins were increased in the intestinal digesta. IgG Fc-binding protein is an abundant protein in the mucus that could be associated with immunity as a component of gel-forming mucins (Johansson and Hansson, 2016). Due to its ability to bind $\operatorname{IgG}$ in the intestinal mucus (Kobayashi et al., 2002), IgG Fc-binding protein may be involved in the trapping and clearance of pathogens and serve as an important component of mucosal immunological defense in neonatal calves. In neonatal calves, RBP1 and RBP2 are retinol transporter proteins that may contribute to the absorption and transport of retinol across the intestine and into the blood. Gel-based proteomics indicated that RBP2 was increased in the jejunum after the calves received colostrum (Yang et al., 2019). This is supported by studies reporting that retinol concentration increased in the serum of neonatal calves following colostrum intake (Blum et al., 1997). In addition, several proteins, such as manganese superoxide dismutase and glutathione S-transferase, are correlated with antioxidant activity (Diaz de Barboza et al., 2017) and were also increased in the intestinal digesta. Therefore, our results support the idea that proteins in the colostrum and the intestinal digesta may promote host defense function in neonatal calves.

\section{Unchanged Proteins from Undigested Colostrum or Milk to the Intestinal Digesta}

In this study, levels of several proteins, such as albumin, $\alpha$-1-acid glycoprotein, plasminogen, gelsolin, and $\beta$-2-glycoprotein 1 were not changed in the colostrum or mature milk compared with those in their intestinal digesta. Among them, serum albumin is a natural transport protein with specific binding sites enabling targeted substance delivery of vitamin D, fatty acids, bilirubin, and multiple divalent cations across the intestine (Maares et al., 2018). Due to the role of albumin in biological transport in the intestinal epithelium, we suggest that albumin may contribute to improving nutrient loading and delivery in neonatal calves (Hashem et al., 2018). Gelsolin is involved in the regulation of actin dynamics and contributed to cell survival signaling pathways and host defense (Silacci et al., 2004). The $\alpha-1$-acid glycoprotein, a positive acute-phase protein, was identified in bovine milk and was abundant in early lactation (Yang et al., 2020) and associated with mucus in the gastrointestinal tract (Chirwa et al., 2012). This protein is implicated in modulating phagocytosis and killing of bacteria by bovine polymorphonuclear leukocytes and monocytes (Lecchi et al., 2013). Thus, $\alpha$-1-acid glycoprotein may provide intestinal immune support against pathogen invasion. Taken together, the unchanged proteins circulating in the colostrum and intestinal digesta may support beneficial immunomodulatory and nutritional activities in neonatal calves.

\section{CONCLUSIONS}

In summary, using label-free proteomics techniques we found that colostrum and mature milk proteins exhibited similar behaviors and functions as they passed through the gastrointestinal tract. Our results suggest that multiple physiological functions are associated with colostral hydrolysates and gastrointestinal secreted productions, including the protection of colostral IgG from hydrolysis, the intestinal immune response against pathogen invasion, and nutrient transport for host growth and development. These findings provide new insights into the fate of the colostral proteome and the corresponding proteins secreted into the gastroin- 
testinal tract for the passive transfer of immunity in the first $36 \mathrm{~h}$ of a neonatal calf's life. Our findings expand the knowledge base of the digestive physiology of neonatal calves, contributing to the improvement of bovine colostrum and calf-rearing management.

\section{ACKNOWLEDGMENTS}

The project was supported by the National Natural Science Foundation of China (Beijing, No. 31572434) and the Science and Technology Program of the Anhui Province (No. 201903a06020013). The authors have not stated any conflicts of interest.

\section{REFERENCES}

Blättler, U., H. M. Hammon, C. Morel, C. Philipona, A. Rauprich, V. Romé, I. Le Huërou-Luron, P. Guilloteau, and J. W. Blum. 2001. Feeding colostrum, its composition and feeding duration variably modify proliferation and morphology of the intestine and digestive enzyme activities of neonatal calves. J. Nutr. 131:1256-1263. https://doi.org/10.1093/jn/131.4.1256.

Blum, J. W., U. Hadorn, H. P. Sallmann, and W. Schuep. 1997. Delaying colostrum intake by one day impairs plasma lipid, essential fatty acid, carotene, retinol and alpha-tocopherol status in neonatal calves. J. Nutr. 127:2024-2029. https://doi.org/10.1093/jn/ 127.10.2024.

Bueno-Gavilá, E., A. Abellán, F. Girón-Rodríguez, J. M. Cayuela, E. Salazar, R. Gómez, and L. Tejada. 2019. Bioactivity of hydrolysates obtained from bovine casein using artichoke (Cynara scolymus L.) proteases. J. Dairy Sci. 102:10711-10723. https://doi.org/ 10.3168/jds.2019-16596.

Cao, X., M. Yang, N. Yang, X. Liang, D. Tao, B. Liu, J. Wu, and X. Yue. 2019. Characterization and comparison of whey N-glycoproteomes from human and bovine colostrum and mature milk. Food Chem. 276:266-273. https://doi.org/10.1016/j.foodchem.2018.09 .174 .

Chirwa, N., D. Govender, B. Ndimba, Z. Lotz, M. Tyler, E. Panieri, D. Kahn, and A. S. Mall. 2012. A 40-50kDa glycoprotein associated with mucus is identified as alpha-1-acid glycoprotein in carcinoma of the stomach. J. Cancer 3:83-92. https://doi.org/10.7150/jca .3737 .

Christensen, B., N. J. Karlsen, S. D. S. Jørgensen, L. N. Jacobsen, M. S. Ostenfeld, S. V. Petersen, A. Müllertz, and E. S. Sørensen. 2020. Milk osteopontin retains integrin-binding activity after in vitro gastrointestinal transit. J. Dairy Sci. 103:42-51. https://doi.org/ $10.3168 /$ jds.2019-17212.

Christensen, S., T. Wiegers, J. Hermansen, and L. Sottrup-Jensen. 1995. Plasma-derived protease inhibitors in bovine milk. Int. Dairy J. 5:439-449. https://doi.org/10.1016/0958-6946(95)00020-4.

Cox, J., and M. Mann. 2008. MaxQuant enables high peptide identification rates, individualized p.p.b.-range mass accuracies and proteome-wide protein quantification. Nat. Biotechnol. 26:1367-1372. https://doi.org/10.1038/nbt.1511.

D'Alessandro, A., L. Zolla, and A. Scaloni. 2011. The bovine milk proteome: Cherishing, nourishing and fostering molecular complexity. An interactomics and functional overview. Mol. Biosyst. 7:579-597. https://doi.org/10.1039/C0MB00027B.

Dallas, D. C., N. M. Murray, and J. Gan. 2015. Proteolytic systems in milk: Perspectives on the evolutionary function within the mammary gland and the infant. J. Mammary Gland Biol. Neoplasia 20:133-147. https://doi.org/10.1007/s10911-015-9334-3.

Danielsen, M., L. J. Pedersen, and E. Bendixen. 2011. An in vivo characterization of colostrum protein uptake in porcine gut during early lactation. J. Proteomics 74:101-109. https://doi.org/10 .1016/j.jprot.2010.08.011.
Demers-Mathieu, V., S. D. Nielsen, M. A. Underwood, R. Borghese, and D. C. Dallas. 2018. Changes in proteases, antiproteases, and bioactive proteins from mother's breast milk to the premature infant stomach. J. Pediatr. Gastroenterol. Nutr. 66:318-324. https:/ /doi.org/10.1097/MPG.0000000000001719.

Diaz de Barboza, G., S. Guizzardi, L. Moine, and N. Tolosa de Talamoni. 2017. Oxidative stress, antioxidants and intestinal calcium absorption. World J. Gastroenterol. 23:2841-2853. https://doi .org/10.3748/wjg.v23.i16.2841.

Enjapoori, A. K., S. Kukuljan, K. M. Dwyer, and J. A. Sharp. 2019. In vivo endogenous proteolysis yielding beta-casein derived bioactive beta-casomorphin peptides in human breast milk for infant nutrition. Nutrition 57:259-267. https://doi.org/10.1016/j.nut.2018.05 .011 .

Fahey, M. J., A. J. Fischer, M. A. Steele, and S. L. Greenwood. 2020. Characterization of the colostrum and transition milk proteomes from primiparous and multiparous Holstein dairy cows. J. Dairy Sci. 103:1993-2005. https://doi.org/10.3168/jds.2019-17094.

Fischer, A. J., Y. Song, Z. He, D. M. Haines, L. L. Guan, and M. A. Steele. 2018. Effect of delaying colostrum feeding on passive transfer and intestinal bacterial colonization in neonatal male Holstein calves. J. Dairy Sci. 101:3099-3109. https://doi.org/10.3168/jds 2017-13397.

Gardell, S. J., C. S. Craik, E. Clauser, E. J. Goldsmith, C. B. Stewart, M. Graf, and W. J. Rutter. 1988. A novel rat carboxypeptidase, CPA2: Characterization, molecular cloning, and evolutionary implications on substrate specificity in the carboxypeptidase gene family. J. Biol. Chem. 263:17828-17836.

Haiwen, Z., H. Rui, Z. Bingxi, G. Qingfeng, Z. Jifeng, W. Xuemei, and W. Beibei. 2019. Oral administration of bovine lactoferrin-derived lactoferricin (Lfcin) B could attenuate enterohemorrhagic Escherichia coli $\mathrm{O} 157: \mathrm{H} 7$ induced intestinal disease through improving intestinal barrier function and microbiota. J. Agric. Food Chem. 67:3932-3945. https://doi.org/10.1021/acs.jafc.9b00861.

Hashem, L., M. Swedrowska, and D. Vllasaliu. 2018. Intestinal uptake and transport of albumin nanoparticles: Potential for oral delivery. Nanomedicine (Lond.) 13:1255-1265. https://doi.org/10 $.2217 / \mathrm{nnm}-2018-0029$.

Heinrich, M., and U. Kulozik. 2011. Study of chymosin hydrolysis of casein micelles under ultra high pressure: Effect on re-association upon pressure release. Int. Dairy J. 21:664-669. https://doi.org/10 $.1016 /$ j.idairyj.2011.02.003.

Jiang, R., and B. Lönnerdal. 2016. Biological roles of milk osteopontin. Curr. Opin. Clin. Nutr. Metab. Care 19:214-219.

Johansson, M. E. V., and G. C. Hansson. 2016. Immunological aspects of intestinal mucus and mucins. Nat. Rev. Immunol. 16:639-649. https://doi.org/10.1038/nri.2016.88.

Kertz, A. F., T. M. Hill, J. D. Quigley 3rd, A. J. Heinrichs, J. G. Linn, and J. K. Drackley. 2017. A 100-year review: Calf nutrition and management. J. Dairy Sci. 100:10151-10172. https://doi.org/10 $.3168 /$ jds.2017-13062.

Kobayashi, K., H. Ogata, M. Morikawa, S. Iijima, N. Harada, T. Yoshida, W. R. Brown, N. Inoue, Y. Hamada, H. Ishii, M. Watanabe, and T. Hibi. 2002. Distribution and partial characterisation of IgG Fc binding protein in various mucin producing cells and body fluids. Gut 51:169-176. https://doi.org/10.1136/gut.51.2.169.

Law, R. H. P., D. Abu-Ssaydeh, and J. C. Whisstock. 2013. New insights into the structure and function of the plasminogen/plasmin system. Curr. Opin. Struct. Biol. 23:836-841. https://doi.org/10 $.1016 /$ j.sbi.2013.10.006.

Lecchi, C., A. Scarafoni, V. Bronzo, P. A. Martino, A. Cavallini, P. Sartorelli, and F. Ceciliani. 2013. $\alpha_{1}$-Acid glycoprotein modulates phagocytosis and killing of Escherichia coli by bovine polymorphonuclear leucocytes and monocytes. Vet. J. 196:47-51. https://doi .org/10.1016/j.tvjl.2012.07.022.

Liu, G., S. Sun, B. Guo, B. Miao, Z. Luo, Z. Xia, D. Ying, F. Liu, B. Guo, J. Tang, Y. Cao, and J. Miao. 2018. Bioactive peptide isolated from casein phosphopeptides promotes calcium uptake in vitro and in vivo. Food Funct. 9:2251-2260. https://doi.org/10 .1039/C7FO01709J. 
Liu, L., R. Jiang, and B. Lönnerdal. 2019. Assessment of bioactivities of the human milk lactoferrin-osteopontin complex in vitro. J. Nutr. Biochem. 69:10-18. https://doi.org/10.1016/j.jnutbio.2019 .03.016.

Maares, M., A. Duman, C. Keil, T. Schwerdtle, and H. Haase. 2018. The impact of apical and basolateral albumin on intestinal zinc resorption in the Caco-2/HT-29-MTX co-culture model. Metallomics 10:979-991. https://doi.org/10.1039/C8MT00064F.

McGrath, B. A., P. F. Fox, P. L. H. McSweeney, and A. L. Kelly. 2016. Composition and properties of bovine colostrum: a review. Dairy Sci. Technol. 96:133-158. https://doi.org/10.1007/s13594 -015-0258-x.

Miyazaki, T., K. Okada, T. Yamashita, and M. Miyazaki. 2017. Twodimensional gas chromatography time-of-flight mass spectrometrybased serum metabolic fingerprints of neonatal calves before and after first colostrum ingestion. J. Dairy Sci. 100:4354-4364. https: //doi.org/10.3168/jds.2017-12557.

Morgan, A. J., L. G. Riley, P. A. Sheehy, and P. C. Wynn. 2014. The influence of protein fractions from bovine colostrum digested in vivo and in vitro on human intestinal epithelial cell proliferation. J. Dairy Res. 81:73-81. https://doi.org/10.1017/S0022029913000654.

Neilson, K. A., N. A. Ali, S. Muralidharan, M. Mirzaei, M. Mariani, G. Assadourian, A. Lee, S. C. van Sluyter, and P. A. Haynes. 2011. Less label, more free: Approaches in label-free quantitative mass spectrometry. Proteomics 11:535-553. https://doi.org/10.1002/ pmic.201000553.

Nissen, A., P. H. Andersen, E. Bendixen, K. L. Ingvartsen, and C. M. Røntved. 2017. Colostrum and milk protein rankings and ratios of importance to neonatal calf health using a proteomics approach. J. Dairy Sci. 100:2711-2728. https://doi.org/10.3168/jds.2016-11722.

Nissen, A., E. Bendixen, K. L. Ingvartsen, and C. M. Røntved. 2012 In-depth analysis of low abundant proteins in bovine colostrum using different fractionation techniques. Proteomics 12:2866-2878. https://doi.org/10.1002/pmic.201200231.

Ohtani, S., K. Shirasu, K. Ogawara, K. Higaki, and T. Kimura. 2003. Evaluation of inhibitory activity of casein on proteases in rat intestine. Pharm. Res. 20:611-617. https://doi.org/10.1023/A: 1023298816392.

Piotte, C. P., and M. R. Grigor. 1996. A novel marsupial protein expressed by the mammary gland only during the early lactation and related to the Kunitz proteinase inhibitors. Arch. Biochem. Biophys. 330:59-64. https://doi.org/10.1006/abbi.1996.0225.

Qi, Y., X. Zhao, D. Huang, X. Pan, Y. Yang, H. Zhao, H. Hu, and G. Cheng. 2018. Exploration of the relationship between intestinal colostrum or milk, and serum metabolites in neonatal calves by metabolomics analysis. J. Agric. Food Chem. 66:7200-7208. https: //doi.org/10.1021/acs.jafc.8b01621.

Saldana, D. J., S. L. Gelsinger, C. M. Jones, and A. J. Heinrichs. 2019. Effect of different heating times of high-, medium-, and low-quality colostrum on immunoglobulin $\mathrm{G}$ absorption in dairy calves. J. Dairy Sci. 102:2068-2074. https://doi.org/10.3168/jds.2018-15542.

Shivley, C. B., J. E. Lombard, N. J. Urie, D. M. Haines, R. Sargent, C. A. Kopral, T. J. Earleywine, J. D. Olson, and F. B. Garry. 2018. Preweaned heifer management on US dairy operations: Part II. Factors associated with colostrum quality and passive transfer status of dairy heifer calves. J. Dairy Sci. 101:9185-9198. https:// doi.org/10.3168/jds.2017-14008

Silacci, P., L. Mazzolai, C. Gauci, N. Stergiopulos, H. L. Yin, and D. Hayoz. 2004. Gelsolin superfamily proteins: Key regulators of cellular functions. Cell. Mol. Life Sci. 61:2614-2623. https://doi.org/ 10.1007/s00018-004-4225-6.
Tagliazucchi, D., S. Martini, S. Shamsia, A. Helal, and A. Conte. 2018. Biological activities and peptidomic profile of in vitro-digested cow, camel, goat and sheep milk. Int. Dairy J. 81:19-27. https:// doi.org/10.1016/j.idairyj.2018.01.014.

Telang, S. 2018. Lactoferrin: A critical player in neonatal host defense. Nutrients 10:1228. https://doi.org/10.3390/nu10091228.

Tyanova, S., T. Temu, P. Sinitcyn, A. Carlson, M. Y. Hein, T. Geiger, M. Mann, and J. Cox. 2016. The Perseus computational platform for comprehensive analysis of (prote)omics data. Nat. Methods 13:731-740. https://doi.org/10.1038/nmeth.3901.

Vorob'ev, M. M., and K. A. Kochetkov. 2016. Determination of kinetic parameters for casein hydrolysis by chymotrypsin using two ranges of substrate concentration. Int. Dairy J. 61:76-84. https://doi.org/ 10.1016/j.idairyj.2016.04.003.

Yang, Y., E. Anderson, and S. Zhang. 2018. Evaluation of six sample preparation procedures for qualitative and quantitative proteomics analysis of milk fat globule membrane. Electrophoresis 39:23322339. https://doi.org/10.1002/elps.201800042.

Yang, Y., X. Zhao, D. Huang, J. Wang, Y. Qi, L. Jiang, H. Zhao, and G. Cheng. 2019. Changes in intestinal proteins induced by colostrum uptake in neonatal calves: analysis by two-dimensional gel electrophoresis-based proteomics analysis. Anim. Prod. Sci. 59:1483-1490. https://doi.org/10.1071/AN18242.

Yang, Y., N. Zheng, X. Zhao, J. Yang, Y. Zhang, R. Han, S. Zhao, S. Li, F. Wen, and J. Wang. 2020. Changes in whey proteome with lactation stage and parity in dairy cows using a label-free proteomics approach. Food Res. Int. 128:108760. https://doi.org/10 .1016/j.foodres.2019.108760.

Yvon, M., D. Levieux, M. C. Valluy, J. P. Pélissier, and P. P. Mirand. 1993. Colostrum protein digestion in newborn lambs. J. Nutr. 123:586-596. https://doi.org/10.1093/jn/123.3.586.

Zanker, I. A., H. M. Hammon, and J. W. Blum. 2000. Plasma amino acid pattern during the first month of life in calves fed the first colostrum at $0-2 \mathrm{~h}$ or at $24-25 \mathrm{~h}$ after birth. J. Vet. Med. A Physiol. Pathol. Clin. Med. 47:107-121. https://doi.org/10.1046/j .1439-0442.2000.00271.x

Zhao, X. W., Y. X. Qi, D. W. Huang, X. C. Pan, G. L. Cheng, H. L. Zhao, and Y. X. Yang. 2018. Changes in serum metabolites in response to ingested colostrum and milk in neonatal calves, measured by nuclear magnetic resonance-based metabolomics analysis. J. Dairy Sci. 101:7168-7181. https://doi.org/10.3168/jds.2017 $-14287$.

Zheng, L., Q. Xu, L. Lin, X. A. Zeng, B. Sun, and M. Zhao. 2019. In vitro metabolic stability of a casein-derived dipeptidyl peptidaseIV (DPP-IV) inhibitory peptide VPYPQ and its controlled release from casein by enzymatic hydrolysis. J. Agric. Food Chem. 67:10604-10613. https://doi.org/10.1021/acs.jafc.9b03164.

Zwirzitz, A., M. Reiter, R. Skrabana, A. Ohradanova-Repic, O. Majdic, M. Gutekova, O. Cehlar, E. Petrovč́́kova, E. Kutejova, G. Stanek, H. Stockinger, and V. Leksa. 2018. Lactoferrin is a natural inhibitor of plasminogen activation. J. Biol. Chem. 293:8600-8613. https://doi.org/10.1074/jbc.RA118.003145.

\section{ORCIDS}

X. W. Zhao ๑ https://orcid.org/0000-0003-0952-0785

H. L. Zhu ๑ https://orcid.org/0000-0001-5273-5090

Y. X. Yang (1) https://orcid.org/0000-0002-9596-9636 